\title{
The mitochondrial genome of the land snail Cernuella virgata (Da Costa, 1778): the first complete sequence in the family Hygromiidae (Pulmonata, Stylommatophora)
}

\author{
Jun-Hong Lin', Wei-Chuan Zhou², Hong-Li Ding', Pei Wang², Hong-Mu Ai'
}

I College of Plant Protection, Fujian Agriculture and Forestry University, Fuzhou, Fujian 350002, China 2 Key Laboratory of Molluscan Quarantine and Identification of AQSIQ, Fujian Entry-Exit Inspection \& Quarantine Bureau, Fuzhou, Fujian 350001, China

Corresponding authors: Pei Wang (wangpei601@126.com); Hong-MuAi (aihongmu@yahoo.com.cn)

Academic editor: F Köhler | Received 27 December 2015 | Accepted 25 April 2016 | Published 16 May 2016

http://zoobank.org/C251453E-ED89-4EDC-BD2D-7D37F5DAA5D1

Citation: Lin J-H, Zhou W-C, Ding H-L, Wang P, Ai H-M (2016) The mitochondrial genome of the land snail Cernuella virgata (Da Costa, 1778): the first complete sequence in the family Hygromiidae (Pulmonata, Stylommatophora). ZooKeys 589: 55-69. doi: 10.3897/zookeys.589.7637

\begin{abstract}
The land snail Cernuella virgata (da Costa, 1778) is widely considered as a pest to be quarantined in most countries. In this study, the complete mitochondrial genome of $C$. virgata is published. The mitochondrial genome has a length of 14,147 bp a DNA base composition of $29.07 \%$ A, 36.88\% T, $15.59 \%$ C and $18.46 \%$ G, encoding 13 protein-coding genes (PCGs), 22 transfer RNA (tRNA) genes and two ribosomal RNA (rRNA) genes. The complete nucleotide composition was biased toward adenine and thymine, $\mathrm{A}+\mathrm{T}$ accounting for $69.80 \%$. Nine PCGs and 14 tRNA genes are encoded on the J strand, and the other four PCGs and eight tRNA genes are encoded on the $\mathrm{N}$ strand. The genome also includes 16 intergenic spacers. All PCGs start strictly with ATN, and have conventional stop codons (TAA and TAG). All tRNAs fold into the classic cloverleaf structure, except $t R N A^{A r g}, t R N A^{\operatorname{Ser}(U C N)}, t R N A^{\operatorname{Ser}(A G N)}$ and $t R N A^{P_{r o}}$. The first three lack the dihydrouridine arm while the last lacks the $\mathrm{T} \psi \mathrm{C}$ arm. There are $502 \mathrm{bp}$ long noncoding regions and 418bp long gene overlaps in the whole mitochondrial genome, accounting for $3.54 \%$ and $2.95 \%$ of the total length respectively. Phylogenetic analyses based on the sequences of the protein coding genes revealed a sister group relationship between the Hygromiidae and the Helicidae.
\end{abstract}

\section{Keywords}

DNA sequencing, phylogeny, plant quarantine, secondary structure, white snail

Copyright Jun-Hong Lin et al. This is an open access article distributed under the terms of the Creative Commons Attribution License (CC BY 4.0), which permits unrestricted use, distribution, and reproduction in any medium, provided the original author and source are credited. 


\section{Introduction}

The land snail Cernuella virgata (da Costa, 1778), also known as the Mediterranean white snail or Common white snail, is endemic to the Mediterranean and western Europe, and has been introduced to America, Australia and Morocco (Barker 2004). The snail is omnivorous, feeding on detritus and plant matter, such as bark, stems and leaves of various green plants. Not only does it destroy agricultural crops, such as beans, cereal, various fruits and vegetables, it also can spread zoonotic food-borne parasitic diseases. For example, the species acts as intermediate host for the terrestrial trematode parasite Brachylaima cribbi (Kerney and Cameron 1979; Butcher and Grove 2006). Because of its remarkable adaptability and the severe damage it causes to agriculture, the natural environment and humans, the snail is considered a serious pest in the USA, Australia, Japan, Chile and other countries (Dennis 1996; Barker 2004; USDA 2008; MOA and AQSIQ 2012). One ship carrying barley from Australia was refused entry and berthing by Chile because of the presence of this snail causing huge economic losses (USDA 2008). It is also one of the more important quarantine terrestrial mollusks in America. To prevent invasion and proliferation, the U.S. government has invested considerable human and financial resources to eradicate the snails in Washington, Michigan and North Carolina (USDA 2008). Recently, Chinese ports have intercepted snails in barley, rapeseed and other consignments from abroad. Owing to its great harm, the snail was listed in "The People's Republic of China entry plant quarantine pest list" by the government in 2012 to prevent its introduction (MOA and AQSIQ 2012).

The metazoan mitochondrial (mt) genome usually comprise 37 genes and some noncoding regions, such as 13 protein coding genes (PCGs) (COI-COIII, Cytb, ND1-ND6, ND4L, ATP6 and ATP8), two ribosomal RNA (rRNA) genes, 22 transfer RNA (tRNA) genes and the AT-rich region or control region (Wolstenholme 1992; Boore 1999). It has been extensively used to study the origin of species, phylogeography and population genetic structure and so on due to its small genome size, fast evolution, uniparental inheritance and lack of extensive recombination (Saccone et al. 1999; Elmerot et al. 2002). To date, only nine species from the order Stylommatophora have been determined as dispersing in Helicidae (Terrett et al. 1995; Groenenberg et al. 2012; Gaitán-Espitia et al. 2013), Bradybaenidae (Yamazaki et al. 1997; Deng et al. 2014), Clausiliidae (Hatzoglou et al. 1995), Succineidae (White et al. 2011), Achatinidae (He et al. 2014) and Camaenidae (Wang et al. 2014). However, there are no reports on the mt genome of the family Hygromiidae. In this work, the complete $\mathrm{mt}$ genome of the snail $C$. virgata was obtained firstly using primer walking and shotgun sequencing techniques based on PCR. Studying the mitochondrial genome of $C$. virgata can not only offer more worthwhile information for phylogeny but also be applied to molecular alignment and identification in international plant quarantine measures. 


\section{Materials and methods}

\section{Specimen collection and DNA isolation}

Adult snail was intercepted from barley shipments imported to China from southern Australia on 1 March 2012 and stored at $-20{ }^{\circ} \mathrm{C}$ in the Key Laboratory of Molluscan Quarantine and Identification of AQSIQ, Fujian Entry-Exit Inspection \& Quarantine Bureau, Fuzhou, Fujian, China (FJIQBC). Voucher specimens (FJIQBC000123) were deposited in FJIQBC. Total genomic DNA was obtained from approximately $50 \mathrm{mg}$ fresh foot tissue, using the DNeasy Blood and Tissue kit (Qiagen) according to the manufacturer's instructions.

\section{DNA sequencing}

The entire genome was successfully amplified by polymerase chain reaction (PCR) in overlapping fragments with four pairs of mitochondrial universal primers chosen from previous works (Palumbi et al. 1991; Folmer et al. 1994; Merritt et al. 1998; Hugall et al. 2002) and four pairs of perfectly matched primers designed from sequenced short fragments with Primer Premier 5.0 (Table 1). Short PCRs $(<2 \mathrm{~kb})$ were performed using Takara Taq DNA polymerase (TaKaRa, Dalian, China), with the following cycling conditions: 30 s at $94^{\circ} \mathrm{C}$, followed by 35 cycles of 10 s at $94^{\circ} \mathrm{C}, 50$ s at $40^{\circ} \mathrm{C}$ or $45^{\circ} \mathrm{C}$, and $1 \mathrm{~min}$ at $72^{\circ} \mathrm{C}$. The final elongation step was continued for $10 \mathrm{~min}$ at $72^{\circ} \mathrm{C}$. Long range PCRs ( $>4 \mathrm{~kb}$ ) were performed using Takara Long Taq DNA polymerase (Ta$\mathrm{KaRa}$, Dalian, China) under the following cycling conditions: $1 \mathrm{~min}$ at $94^{\circ} \mathrm{C}$, followed by 40 cycles of $10 \mathrm{~s}$ at $98^{\circ} \mathrm{C}, 50 \mathrm{~s}$ at $60^{\circ} \mathrm{C}, 4-8 \mathrm{~min}$ at $68^{\circ} \mathrm{C}$, and the final elongation step at $72^{\circ} \mathrm{C}$ for $6 \mathrm{~min}$. The PCR products were checked by spectrophotometry and $1.0 \%$ agarose gel electrophoresis.

The BigDye Terminator Sequencing Kit (Applied Biosystems, San Francisco, CA, USA) and the ABI PRIMER ${ }^{\mathrm{TM}}$ 3730XL DNA Analyzer (PE Applied Biosystems) were used to sequence short fragments from both directions after purification. For the long fragments, the shotgun libraries of $C$. virgata were constructed, and the positive clones were then sequenced using the above kit and sequenator with vector-specific primers BcaBest primer M13-47 and BcaBest Primer RV-M.

\section{Genome annotation and inference of secondary structure}

To control sequencing errors, each partial sequence was evaluated at least twice. Annotations and editing procedures of the mitochondrial genomes of $C$. virgata were performed in MEGA5.0. Mitochondrial PCGs and rRNA genes were identified by 
Table I. Primer pairs used for PCR amplification.

\begin{tabular}{c|c|c|c|c}
\hline $\begin{array}{c}\text { No. of } \\
\text { fragment }\end{array}$ & $\begin{array}{c}\text { Primer } \\
\text { name }\end{array}$ & Nucleotide sequence (5'-3') and location & $\begin{array}{c}\text { Size } \\
(\mathbf{b p})\end{array}$ & Reference \\
\hline 1 & LCO-1490 & GGTCAACAAATCATAAAGATATTGG & & Folmer et al. 1994 \\
\hline & HCO-2198 & TAAACTTCAGGGTGACCAAAAAATCA & & Folmer et al. 1994 \\
\hline 2 & F1231 & GAACGGGTTAGTTTGTTTGTCT(490-511) & 1763 & Present study \\
\hline & R1231 & TAGGGTCTTCTCGTCTATTATGGT(2229-2252) & & Present study \\
\hline 3 & 16 ar-L & CGCCTGTTTATCAAAAACAT & & Palumbi et al. 1991 \\
\hline & 16 Sbr-H & CCGGTCTGAACTCAGATCACGT & & Palumbi et al. 1991 \\
\hline 4 & $123 \mathrm{~F} 116$ & TGTAACCATAATAGACGAGAAGACC(2225-2249) & 4545 & Present study \\
\hline & $123 \mathrm{R} 1 \mathrm{~b}$ & TAGGAGCAAAAAATACTACCAGAAA(6745-6769) & & Present study \\
\hline 5 & $144 \mathrm{~F}$ & TGAGSNCARATGTCNTWYTG & & Merritt et al. 1998 \\
\hline & $272 \mathrm{R}$ & GCRAANAGRAARTACCAYTC & & Merritt et al. 1998 \\
\hline 6 & $123 \mathrm{Fb}$ & CTTTTCACCCCTACTTTAC(6683-6701) & 1044 & Present study \\
\hline & $123 \mathrm{RII}$ & ACTCCCTTTCAGGTGTTAT(7708-7726) & & Present study \\
\hline 7 & FCOII & AAATAATGCTATTTCATGAYCAYG & & Hugall et al. 2002 \\
\hline & RCOII & GCTCCGCAAATCTCTGARCAYTG & & Hugall et al. 2002 \\
\hline 8 & F1233 & AGTTACATTGGCCCTCCCTAGTCTTCGC(7560-7587) & 6930 & Present study \\
\hline & R1233 & GTAAACGGTTCAACCTGTACCAGCTCCC(315-342) & & Present study \\
\hline & & & & \\
\hline
\end{tabular}

BLAST searches at NCBI against other Eupulmonata sequences (Wang et al. 2014; He et al. 2014; Deng et al. 2014; Yang et al. 2014). The limits of both protein coding and rRNA genes were adjusted manually based on location of adjacent genes, and the presence of start and stop codons. The tRNA genes were located using DOGMA (Wyman et al. 2004) and tRNAscan-SE v.1.21(Lowe and Eddy 1997), while others that could not be determined by DOGMA and tRNAscan-SE were identified by comparison with other land snails (Terrett et al. 1995; Yamazaki et al. 1997; Groenenberg et al. 2012; Gaitán-Espitia et al. 2013; Wang et al. 2014).

The base composition and codon usage were analyzed with MEGA 5.0 (Tamura et al. 2007). AT skew and GC skew were used to describe strand asymmetry according to the formulae $A T=[A-T] /[A+T]$ and $G C=[G-C] /[G+C]$ (Perna and Kocher 1995).

\section{Phylogenetic analyses}

Phylogenetic analyses were performed based on 15 complete mt genomes of gastropods from GenBank (Table 2) using maximum likelihood (ML) method. Two species from Basommatophora and Opisthobranchia were selected as outgroups. A DNA alignment with 10,362 bp length was inferred from the amino acid alignment of 13 PCGs using MEGA 5.0 (Tamura et al. 2007). The selection of best-fit-substitution model for ML estimation was performed using MEGA 5.0 with corrected Akaike information criterion (AIC). Node supports for ML analyses were calculated through 1000 bootstrap replicates. All other settings were kept as default. 
Table 2. Summary of samples used in this study.

\begin{tabular}{|c|c|c|c|c|}
\hline Subclass /order & Family & Species & Accession number & Reference \\
\hline \multirow{13}{*}{ Stylommatophora } & Hygromiidae & Cernuella virgata & KR736333 & Present study \\
\hline & \multirow{2}{*}{ Camaenidae } & Camaena cicatricosa & KM365408 & Wang et al. 2014 \\
\hline & & Camaena sp. & KT001074 & Ding et al. 2015 (submitted) \\
\hline & \multirow{4}{*}{ Bradybaenidae } & Euhadra herklotsi & Z71693-Z71701 & Yamazaki et al. 1997 \\
\hline & & Mastigeulota kiangsinensis & KM083123 & Deng et al. 2014 \\
\hline & & Aegista diversifamilia & KR002567.1 & Huang et al.2015 \\
\hline & & Dolicheulota formosensis & KR338956.1 & Huang et al.2015 \\
\hline & \multirow{3}{*}{ Helicidae } & Cornu aspersum & JQ417195 & Gaitán-Espitia et al. 2013 \\
\hline & & Cepaea nemoralis & CMU23045 & Terrett et al. 1995 \\
\hline & & Cylindrus obtusus & JN107636 & Groenenberg et al. 2012 \\
\hline & Succineidae & Succinea putris & JN627206 & White et al. 2011 \\
\hline & Clausiliidae & Albinaria caerulea & $\mathrm{X} 83390$ & White et al. 2011 \\
\hline & Achatinidae & Achatina fulica & $\mathrm{NC} 024601$ & He et al. 2014 \\
\hline Basommatophora & Lymnaeidae & Galba pervia & JN564796 & Liu et al. 2012 \\
\hline Opisthobranchia & Aplysiidae & Aplysia californica & AY569552 & Knudsen et al. 2006 \\
\hline
\end{tabular}

\section{Results}

\section{Genome structural features}

The entire circular genome was 14,147 bp in length (GenBank: KR736333), containing 13 PCGs, 22 tRNA genes and two rRNA genes (Figure 1). Twenty-four genes were encoded on the majority coding strand ( $\mathrm{J}$ strand) while 13 genes were encoded on the minority coding strand (N strand) (tRNA $A^{G l n}, t R N A^{\operatorname{Leu}(U U R)}, t R N A^{A s n}, t R N A^{A r g}, t R N A^{G l u}$, tRNA $A^{\mathrm{Met}}, t R N A^{\text {Ser(UCN) }}, t R N A^{\text {Thr }}$, ATP6, ATP8, ND3, COIII and SrRNA) (Table 3). The nucleotide composition of the whole genome was biased toward adenine and thymine, accounting for $69.80 \%$ of base composition (Table 4). Gene overlaps with a total of 418 bp have been found at 14 gene junctions; the longest overlap ( 85 bp) existed between ND5 and ND1. In addition, 502 nucleotides were dispersed in 16 intergenic spacers, the largest of which was 149 bp long between $t R N A^{T r p}$ and $t R N A^{G l y}$. Additionally, two long spacers of $77 \mathrm{bp}$ and $76 \mathrm{bp}$ each were found between ND4L and ND1, $t R N A^{\operatorname{Ser}(U C N)}$ and $t R N A^{\operatorname{Ser}(A G N)}$, respectively. There were seven close gene junctions with no intergenic spacers or overlap (Table 3).

\section{Protein coding genes}

The total length of all PCGs was 10, $977 \mathrm{bp}$, accounting for $77.59 \%$ of the entire $\mathrm{mt}$ genome (Table 4). All PCGs started strictly with the Start Codon ATN (four with ATG, five with ATT, and four with ATA) and ended with the conventional stop codons TAA or TAG. (Table 3). 


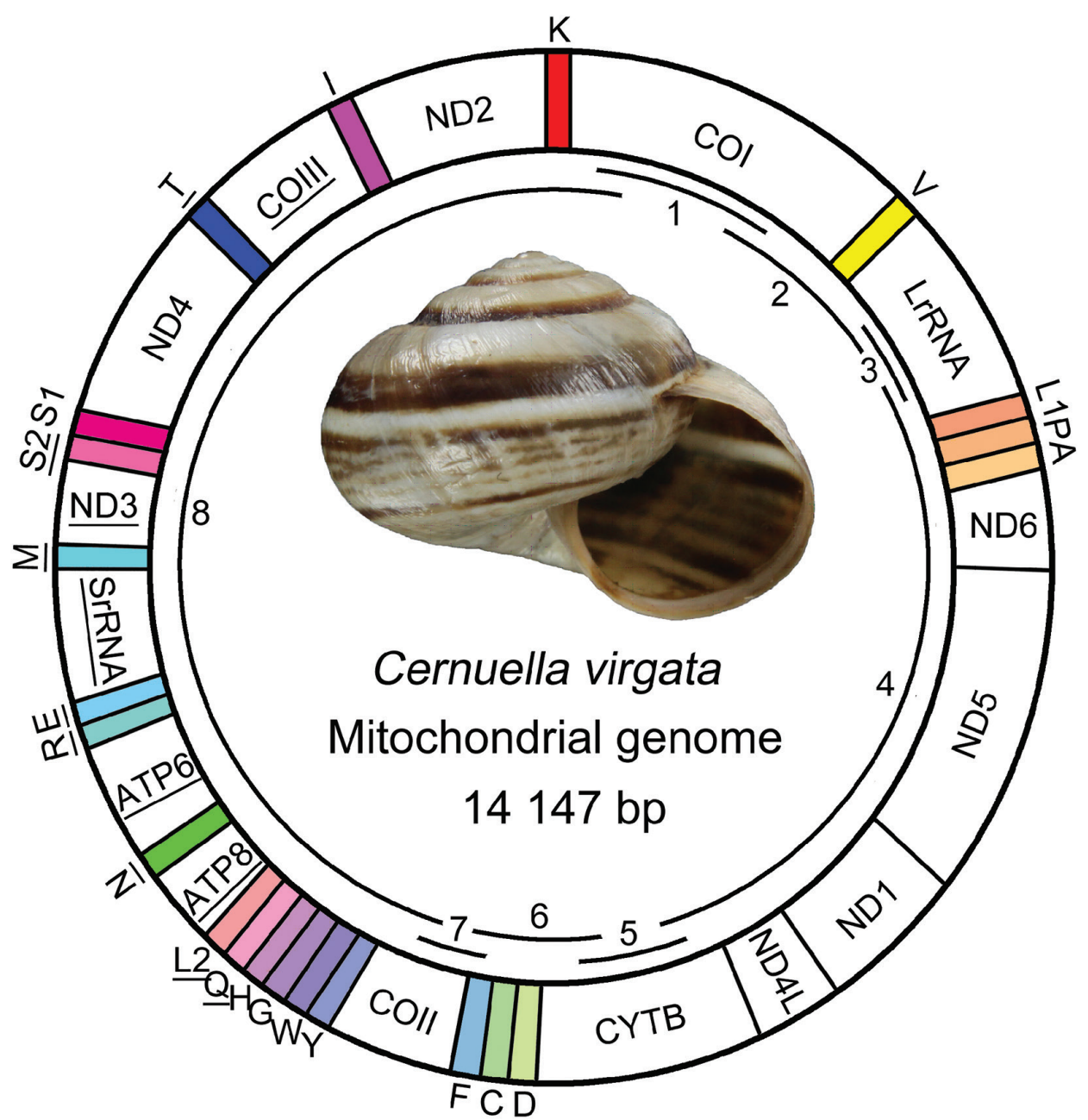

Figure I. The mt genome of Cernuella virgata. The tRNA genes are labeled based on the IUPACIUB single letter amino acid codes. Genes with underline illustrate the direction of transcription from 3' to 5', and without underline revealing from ' 5' to 3'. Numbers and overlapping lines within the circle indicate PCR fragments amplified for sequencing (see Table 1).

Codon usage could reveal nucleotide bias. NNA and NNU as codons were used frequently in most PCGs. Additionally, the codons TTT (phenylalanine), TTA (leucine) and ATT (isoleucine) composing A and T were used widely (Figure 2).

\section{Transfer RNA genes}

The length of tRNA genes ranged from 53 to 69 bp. The 22 tRNA genes typically found in metazoan $\mathrm{mt}$ genomes were also discovered in C. virgata; eleven of them 
Table 3. Organization of the Cernuella virgata mt genome.

\begin{tabular}{|c|c|c|c|c|c|c|c|}
\hline Gene & Direction & Location & Size (bp) & Anticodon & Start codon & Stop codon & \begin{tabular}{|c}
$\begin{array}{c}\text { Intergenic } \\
\text { nucleotides }\end{array}$ \\
\end{tabular} \\
\hline $\mathrm{COI}$ & $\mathrm{F}$ & $1-1497$ & 1497 & & ATT & TAA & 26 \\
\hline$t R N A^{V a l}$ & $\mathrm{~F}$ & 1494-1554 & 61 & 1524-1526 TAC & & & -4 \\
\hline $\operatorname{lr} R N A$ & $\mathrm{~F}$ & $1555-2567$ & 1013 & & & & 0 \\
\hline$t R N A^{\operatorname{Leu}(C U N)}$ & $\mathrm{F}$ & $2568-2628$ & 61 & 2597-2599 TAG & & & 0 \\
\hline$t R N A^{P r o}$ & $\mathrm{~F}$ & $2629-2685$ & 57 & 2655-2657 TGG & & & 0 \\
\hline$t R N A^{A l a}$ & F & $2687-2748$ & 62 & 2718-2720 TGC & & & 1 \\
\hline ND6 & $\mathrm{F}$ & $2767-3222$ & 456 & & ATA & TAA & 18 \\
\hline ND5 & $\mathrm{F}$ & $3227-4888$ & 1662 & & ATT & TAA & 4 \\
\hline ND1 & F & $4804-5769$ & 966 & & ATG & TAG & -85 \\
\hline$N D 4 L$ & $\mathrm{~F}$ & $5847-6215$ & 369 & & ATT & TAA & 77 \\
\hline$C y t B$ & F & $6151-7167$ & 1017 & & ATA & TAG & -65 \\
\hline$t R N A^{A s p}$ & $\mathrm{~F}$ & $7157-7214$ & 58 & 7188-7190 GTC & & & -11 \\
\hline$t R N A^{C y s}$ & $\mathrm{~F}$ & $7215-7276$ & 62 & 7245-7247 GCA & & & 0 \\
\hline$t R N A^{\text {Phe }}$ & $\mathrm{F}$ & $7283-7341$ & 59 & 7313-7315 GAA & & & 6 \\
\hline COII & $\mathrm{F}$ & $7387-8031$ & 645 & & ATT & TAA & 45 \\
\hline$t R N A^{T_{y r}}$ & $\mathrm{~F}$ & $8015-8083$ & 69 & 8046-8048 GTA & & & -17 \\
\hline$t R N A^{T^{T} p}$ & $\mathrm{~F}$ & $8071-8132$ & 62 & 8102-8104 TCA & & & -13 \\
\hline$t R N A^{G l y}$ & $\mathrm{~F}$ & $8282-8341$ & 60 & 8311-8313 TCC & & & 149 \\
\hline$t R N A^{H i s}$ & $\mathrm{~F}$ & $8338-8398$ & 61 & 8369-8371 GTG & & & -4 \\
\hline$t R N A^{G / n}$ & $\mathrm{R}$ & $8400-8457$ & 58 & 8427-8429 TTG & & & 1 \\
\hline$t R N A^{\operatorname{Leu}(U U R)}$ & $\mathrm{R}$ & $8457-8513$ & 57 & 8485-8487 TAA & & & -1 \\
\hline ATP8 & $\mathrm{R}$ & $8485-8754$ & 270 & & ATG & TAA & -29 \\
\hline$t R N A^{A s n}$ & $\mathrm{R}$ & $8743-8804$ & 62 & 8771-8773 GTT & & & -12 \\
\hline ATP6 & $\mathrm{R}$ & $8807-9472$ & 666 & & ATG & TAA & 2 \\
\hline$t R N A^{A r g}$ & $\mathrm{R}$ & $9458-9517$ & 60 & 9489-9491 TCG & & & -15 \\
\hline$t R N A^{\text {Glu }}$ & $\mathrm{R}$ & $9518-9578$ & 61 & 9547-9549 TTC & & & 0 \\
\hline SrRNA & $\mathrm{R}$ & 9579-10277 & 699 & & & & 0 \\
\hline$t R N A^{\text {Met }}$ & $\mathrm{R}$ & 10278-10343 & 66 & 10306-10308 CAT & & & 0 \\
\hline ND3 & $\mathrm{R}$ & $10304-10735$ & 432 & & ATA & TAA & -40 \\
\hline$t R N A^{\operatorname{Ser}(U C N)}$ & $\mathrm{R}$ & 10691-10743 & 53 & 10723-10725 TGA & & & -45 \\
\hline$t R N A^{\operatorname{Ser}(A G N)}$ & $\mathrm{F}$ & 10820-10880 & 61 & 10844-10846 GCT & & & 76 \\
\hline ND4 & $\mathrm{F}$ & 10904-12178 & 1275 & & ATT & TAG & 23 \\
\hline$t R N A^{T h r}$ & $\mathrm{R}$ & $12182-12246$ & 65 & 12210-12212 TGT & & & 3 \\
\hline COIII & $\mathrm{R}$ & 12170-13051 & 882 & & ATG & TAA & -77 \\
\hline$t R N A^{\text {Ile }}$ & $\mathrm{F}$ & 13068-13127 & 60 & 13096-13098 GAT & & & 16 \\
\hline ND2 & $\mathrm{F}$ & 13182-14060 & 879 & & ATA & TAG & 54 \\
\hline$t R N A^{L y s}$ & $\mathrm{~F}$ & 14062-14121 & 60 & 14090-14092 TTT & & & 1 \\
\hline
\end{tabular}

Note: Negative numbers indicate adjacent gene overlap.

were determined by tRNAscan-SE and eight of them were determined by DOGMA. Another three tRNA genes that could not be detected by the above two programs were identified and passed through comparisons with known patterns of previous research 
Table 4. Nucleotide composition and skewness of the Cernuella virgata mt genome.

\begin{tabular}{c|c|c|c|c|c|c|c|c}
\hline & \multicolumn{7}{|c}{ Proportion of nucleotides } & \\
\hline Feature & \%A & $\mathbf{\% T}$ & $\mathbf{\% G}$ & $\mathbf{\% C}$ & $\mathbf{\% A + T}$ & AT Skew & GC Skew & No. of nucleotides \\
\hline Whole genome & 29.07 & 36.88 & 18.46 & 15.59 & 69.80 & -0.12 & 0.08 & 14147 \\
\hline Protein coding genes & 26.39 & 39.31 & 18.43 & 15.87 & 69.26 & -0.20 & 0.07 & 10977 \\
\hline Protein coding genes (J) & 26.08 & 39.96 & 18.70 & 15.26 & 69.17 & -0.21 & 0.10 & 8739 \\
\hline Protein coding genes (N) & 27.61 & 36.77 & 17.38 & 18.23 & 69.67 & -0.14 & -0.02 & 2034 \\
\hline tRNA genes & 31.46 & 34.23 & 18.73 & 15.58 & 71.41 & -0.04 & 0.09 & 1335 \\
\hline tRNA genes (J) & 29.82 & 34.77 & 20.30 & 15.10 & 70.77 & -0.08 & 0.15 & 788 \\
\hline tRNA genes (N) & 33.82 & 33.46 & 16.45 & 16.27 & 72.54 & 0.01 & 0.01 & 547 \\
\hline rRNA genes & 32.83 & 35.63 & 17.00 & 14.54 & 72.42 & -0.04 & 0.08 & 1712 \\
\hline
\end{tabular}

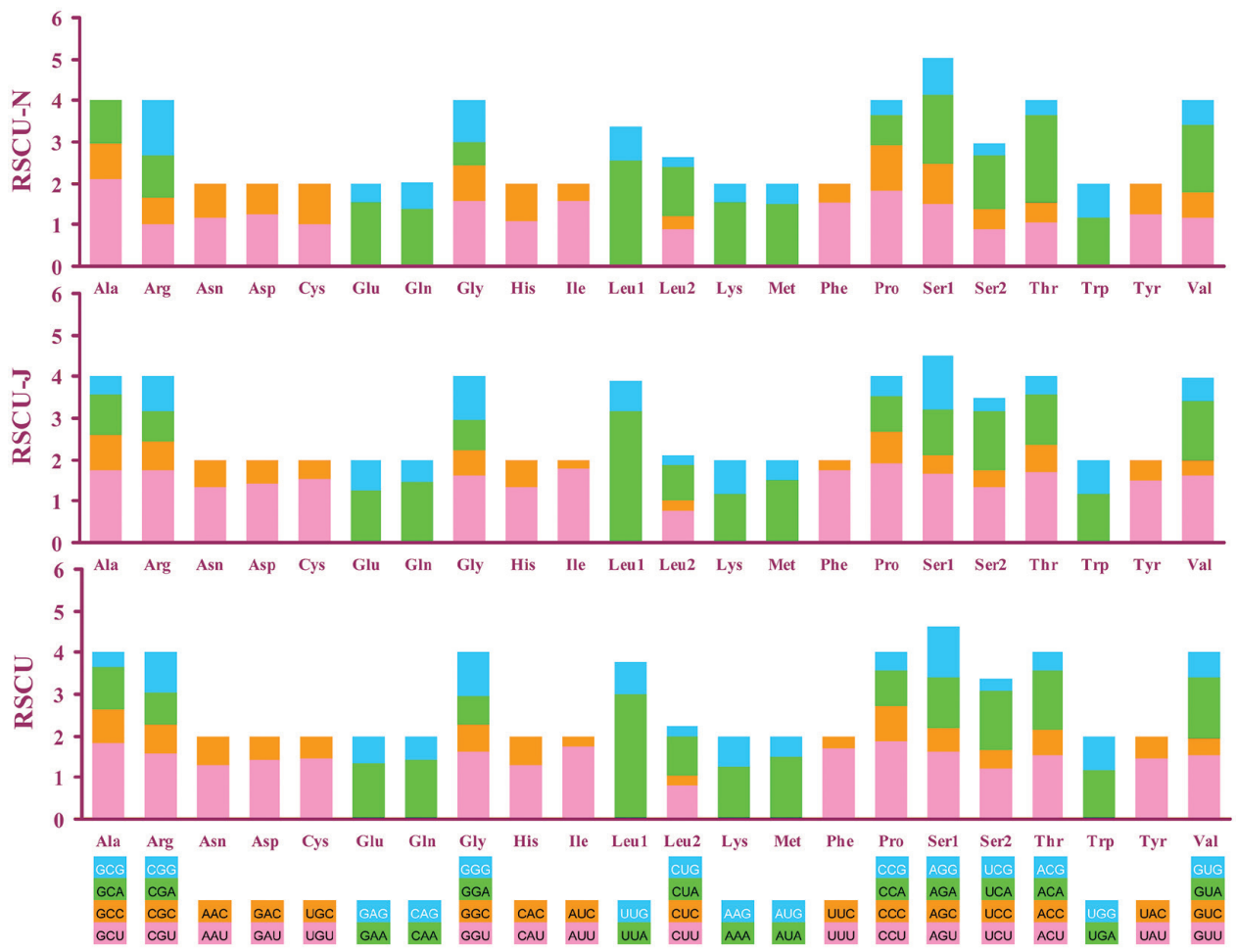

Figure 2. Relative synonymous codon usage (RSCU) in the Cernuella virgata mt genome. Codon families are provided on the $\mathrm{x}$ axis.

Fourteen tRNA genes were encoded on the $\mathrm{J}$ strand and the remainder on the $\mathrm{N}$ strand. Most tRNA genes could be folded into classic clover leaf structures except for $t R N A^{A r g}, t R N A^{\operatorname{Ser}(U C N)}$ and $t R N A^{\operatorname{Ser}(A G N)}$, which lack the dihydrouridine arm. The gene $t R N A^{P r o}$ has a loop in its $\mathrm{T} \psi \mathrm{C}$ arm (Figure 3). 


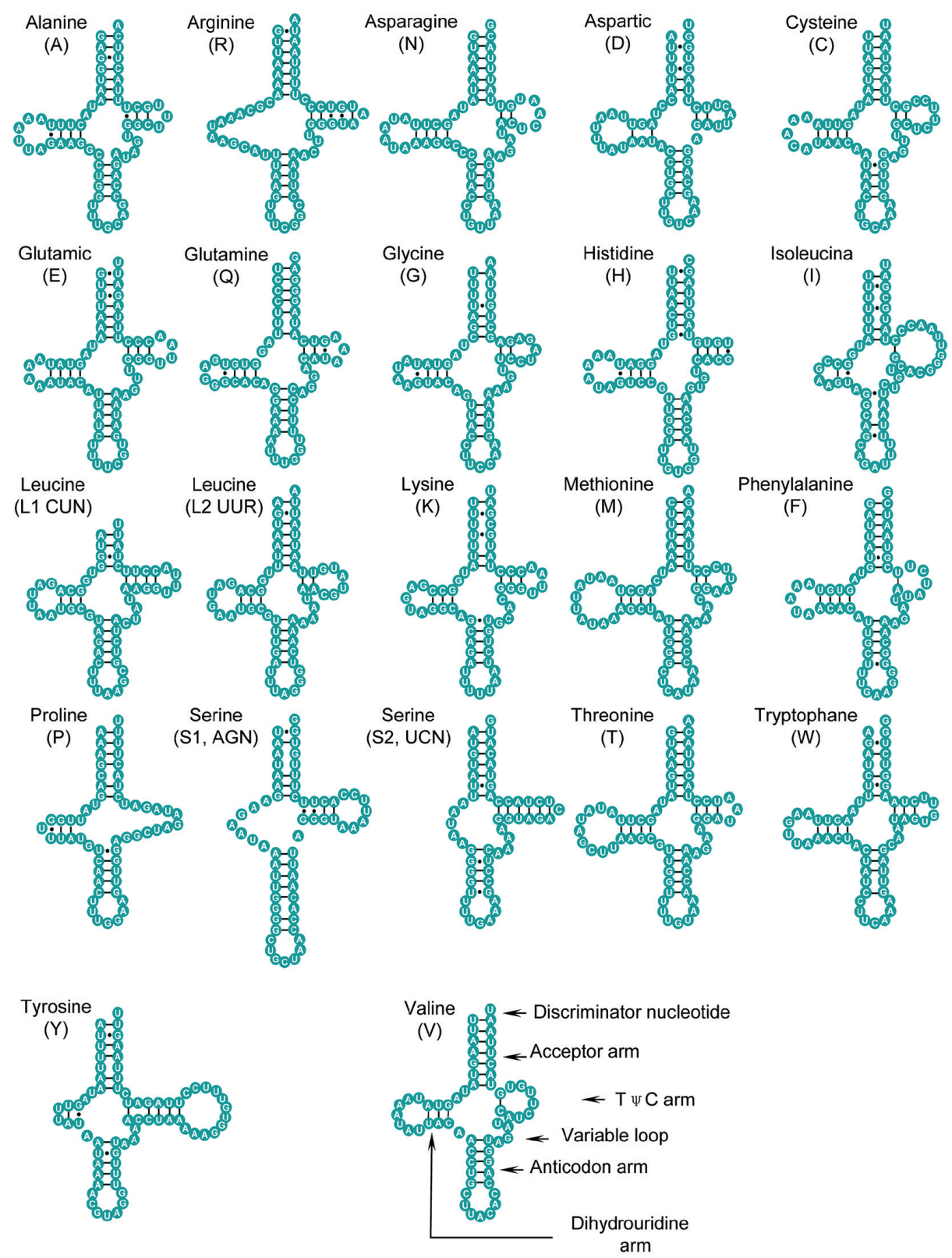

Figure 3. Inferred secondary structures of 22 tRNA genes in Cernuella virgata. Dashes (-) indicate Watson-Crick base pairing and bullets $(\bullet)$ indicate G-U base pairing.

In some tRNA genes, non-Watson-Crick matches and aberrant loops had been found. For example, a total of 41 unmatched base pairs existed in some tRNAs, and 18 of them were G-U non-classical pairs, most of which existed in Discriminator nucleotide, anticodon arm and Dihydrouridine arm (Figure 3). 


\section{Ribosomal RNA genes}

The rRNA genes of $C$. virgata encompassed the $\operatorname{lr} R N A$ and $s r R N A$ genes with a length of $1,013 \mathrm{bp}$ and $699 \mathrm{bp}$, repsectively. The former was situated between $t R N A^{V a l}$ and $t R N A^{\text {Leu(CUN) }}$ and the latter was located between $t R N A^{\text {Glu }}$ and $t R N A^{\text {Met }}$ (Table 3).

\section{Noncoding regions}

In the mitochondrial genome of $C$. virgata, there are 16 noncoding regions with total $502 \mathrm{bp}$ length, accounting for $3.54 \%$. The longest was $149 \mathrm{bp}$, between $t R N A^{T r p}$ and $t R N A^{G l y}$. The shortest was 1 bp existing three regions, respectively locating $t R N A^{P r o}$ and $t R N A^{A l a}, t R N A^{H i s}$ and $t R N A^{G l n}, N D 2$ and $t R N A^{L y s}$ (Table 3).

\section{Phylogenetic reconstruction}

The ML tree (Figure 4) presented nine major clades containing the families Helicidae, Hygromiidae, Camaenidae, Bradybaenidae, Succineidae, Clausiliidae, Achatinidae, Lymnaeidae and Aplysiidae. The four bradybaenid species and three helicid species each formed a clade and a sister pair. In addition, we found that Camaenidae and Bradybaenidae each were monophyletic and also in a sister group relationship with each other.

\section{Discussion}

The length of $\mathrm{mt}$ genome of $C$. virgata was 304 bp longer than Camaena cicatricosa and $97 \mathrm{bp}$ longer than Cornu aspersum. All gene directions showed similarity to the sequenced $\mathrm{mt}$ genome of $C$. cicatricosa, but gene order was different, especially with respect to the positions between CYTB and ATP8 genes (Gaitán-Espitia et al. 2013; Wang et al. 2014). The overall $\mathrm{mt}$ genome of $C$. virgata was loose particularly, with more and longer intergenic spacers.

In the study of $\mathrm{mt}$ genome of $C$. cicatricosa, GTG is the start codon of the COII gene, and COI and NDG genes of C. aspersum start with TTG (Gaitán-Espitia et al. 2013; Wang et al. 2014). From previous studies we can see that most start signals of land snails were consistent with C. virgata factually, but ATC, TTA, TTG, CTT, TCG and CGA as start signals have been found (Raay and Crease 1994; Crease 1999; Yamazaki et al. 1997; Yu et al. 2007; Groenenberg et al. 2012; Gaitán-Espitia et al. 2013; Wang et al. 2014). Conventional stop codons TAA and TAG have been found in all PCGs of $C$. virgata, which corresponds to C. cicatricosa (Wang et al. 2014). However, COII, CYTB, ND3 and ATP8 genes of C. aspersum from the family Helicidae ended with $\mathrm{T}$, and this phenomenon has also been discovered in other snails as 


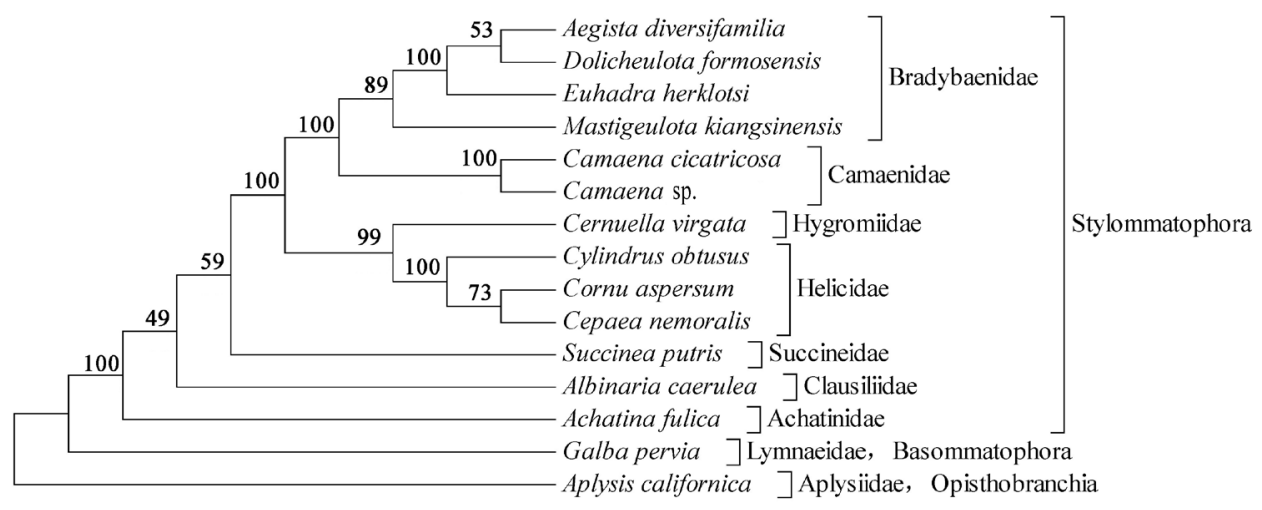

Figure 4. Phylogenetic tree inferred by maximum likelihood (ML) method based on 13 protein genes. The tree is rooted with Aplysis californica and Galba pervia. Numbers on the nodes represent bootstrap values.

well (Terrett et al. 1995; Hatzoglou et al. 1995; Yamazaki et al. 1997; White et al. 2011; Groenenberg et al. 2012; Wang et al. 2012; Gaitán-Espitia et al. 2013). Some authors suggested that this nucleotide exchange was caused by post-transcriptional polyadenylation (Ojala et al. 1981; Cha et al. 2007).

Usually, in the tRNA, the Acceptor arm (7 bp) and Anticodon arm (5 bp) were conservative in size (Kinouchi et al. 2000). However, the length of Acceptor arm of $t R N A^{\operatorname{Leu}(C U N)}$ in C. virgata was distinctive, with only $4 \mathrm{bp}$ in size. The Anticodon arm of tRNA ${ }^{\operatorname{Ser}(A G N)}(8 \mathrm{bp})$ and all Anticodon loops (7 nucleotides) was coincident with the snail C. cicatricosa (Wang et al. 2014). The remaining arms and loops changed apparently in size comparing to that of other land snails (Hatzoglou et al. 1995; Groenenberg et al. 2012; Wang et al. 2014). Some non-Watson-Crick matches existed in all tRNA, including G-U pairs, A-C mismatch, U-C mismatch etc. Tomita et al. (2001) raised that these mismatches may can be rectified by post-transcriptional RNAediting mechanism to hold tRNA function.

Noncoding regions are assumed to splice recognition sites during the process of transcription (He et al. 2005). In the previous sequenced complete $\mathrm{mt}$ genome of the order Stylommatophora, the noncoding regions range from $1 \mathrm{bp}$ to $65 \mathrm{bp}$ (Hatzoglou et al. 1995; Terrett et al. 1995; Yamazaki et al. 1997; White et al. 2011; Groenenberg et al. 2012; Gaitán-Espitia et al. 2013; Deng et al. 2014; Wang et al. 2014) except Achatina fulica with $551 \mathrm{bp}$ length (He et al. 2014). In metazoan mt genomes, these noncoding regions are normal. The longest one can be called control region or AT-rich region (Boore 1999). Usually, changes in length of the whole mt genome are mainly caused by difference of the control region (Zhang and Hewitt 1997). However, the control region may not be aligned accurately in gastropods (Groenenberg et al. 2012) except in $A$. fulica which included a 551 bp putative control region (POR) between $C O I$ and $t R N A^{\text {Val }}$ (He et al. 2014). Another ten sequenced stylommatophoran species may possess short putative control region located in different places (Hatzoglou et al. 1995; Terrett et al. 1995; Yamazaki et al. 1997; White et al. 2011; Groenenberg et 
al. 2012; Gaitán-Espitia et al. 2013; Deng et al. 2014; Wang et al. 2014; Huang et al. 2015; 2015). The PORs of C. virgata, Mastigeulota kiangsinensis and Dolicheulota formosensis are situated adjacent to $t R N A^{\text {Trp }}$, at $149 \mathrm{bp}, 216 \mathrm{bp}$ and $245 \mathrm{bp}$ respectively. The PORs of C. cicatricosa (29 bp) and Succinea putris (48 bp) were located between COIII and $t R N A^{I l e}$. Two other helicid species had PORs located between COIII and $t R N A^{\text {Ser }}$ with lengths of 158-186 bp, whereas the PORs of Albinaria caerulea (65 bp), Aegista diversifamilia (93 bp), Cylindrus obtusus (395 bp) and Euhadra herklotsi (78 bp) were specific, respectively between $N D 3$ and $t R N A^{\text {Ser }}, t R N A^{\text {Met }}$ and $t R N A^{\text {Ser }}, N D 5$ and $t R N A^{A l a}, t R N A^{\operatorname{Ser}(U C N)}$ and $t R N A^{\operatorname{Ser}(A G N)}$. The absence of a control region was consistent with other gastropods (Deng et al. 2014; Wang et al. 2014; Yang et al. 2014). In the present study, the longest noncoding region was $149 \mathrm{bp}$, which was the second longest one by far.

Three species in the Helicidae were sister groups and consistent with previous works (Gaitán-Espitia et al. 2013). However, the systematics of Camaenidae, Helicidae and Bradybaenidae are complicated and have not been fully resolved; systematic and phylogenetic studies based on analyses of morphological and molecular markers have produced inconsistent results (Scott 1996; Cuezzo 2003; Wade et al. 2007; Hirano et al. 2014). More complete taxon sampling need to be prepared to assess the phylogenetic relationship of these three families.

\section{Acknowledgments}

We sincerely thank professor De-Niu Chen of Institute of Zoology, Chinese Academy of Science for helpful comments on the manuscript. We thank the reviewers and the subject editor for their very helpful suggestions on the manuscript. This research is supported by National Natural Science Foundation of China (31372162), Natural Science Foundation in Fujian Province (2015J05076) and Public Science and Technology Research Funds Projects of General Administration of Quality Supervision, Inspection and Quarantine of the People's Republic of China (201410076, 2015IK042).

\section{References}

Barker GM (2004) Natural Enemies of Terrestrial Molluscs. CABI Publishing, London, 644 pp. doi: $10.1079 / 9780851993195.0000$

Boore JL (1999) Animal mitochondrial genomes. Nucleic Acids Research 27(8): 1767-1780. doi: $10.1093 / \mathrm{nar} / 27.8 .1767$

Boore JL (2006) The complete sequence of the mitochondrial genome of Nautilus macromphalus (Mollusca: Cephalopoda). BMC Genomics 7: 182. doi: 10.1186/1471-2164-7-182

Butcher AR, Grove DI (2006) Seasonal variation in rates of sporocyst and metacercarial infection by Brachylaima cribbi in helicid and hygromiid land snails on the Yorke Peninsula, South Australia. Australian Journal of Zoology 53(6): 375-382. doi: 10.1071/ZO05054 
Cha SY, Yoon HJ, Lee EM, Yoon MH, Hwang JS, Jin BR, Han YS, Kim I (2007) The complete nucleotide sequence and gene organization of the mitochondrial genome of the bumblebee, Bombus ignitus (Hymenoptera: Apidae). Gene 392: 206-220. doi: 10.1016/j. gene.2006.12.031

Crease TJ (1999) The complete sequence of the mitochondrial genome of Dapnia pulex (Cladocera: Crustacea). Gene 233: 89-99. doi: 10.1016/S0378-1119(99)00151-1

Deng PJ, Wang WM, Huang XC, Wu XP, Xie GL, Ouyang S (2016) The complete mitochondrial genome of Chinese land snail Mastigeulota kiangsinensis (Gastropoda: Pulmonata: Bradybaenidae). Mitochondrial DNA 27(2): 1084-1085. doi: 10.3109/19401736.2014.953083

Dennis H (1996) Snails: A Quarantine Concern for Export Citrus to the USA. Entomology Unit, SARDI, Australia.

Elmerot C, Arnason U, Gojobori T (2002) The mitochondrial genome of the pufferfish, Fugu rubripes, and ordinal teleostean relationships. Gene 295(2): 163-172. doi: 10.1016/ s0378-1119(02)00688-1

Folmer O, Black M, Hoeh W, Lutz R, Vrijenhoek R (1994) DNA primers for amplification of mitochondrial cytochrome c oxidase subunit I from diverse metazoan invertebrates. Molecular Marine Biology and Biotechnology 3: 294-299.

Gaitán-Espitia JD, Scheihing R, Poulin E, Artacho P, Nespolo RF (2013) Mitochondrial phylogeography of the land snail Cornu aspersum: tracing population history and the impact of human-mediated invasion in austral South America. Evolutionary Ecology Research 15: $1-18$.

Grande C, Templado J, Cervera JL, Zardoya R (2002) The complete mitochondrial genome of the nudibranch Roboastra europaea (Mollusca: Gastropoda) supports the monophyly of opisthobranchs. Molecular Biology and Evolution 19(10): 1672-1685. doi: 10.1093/ oxfordjournals.molbev.a003990

Groenenberg DSJ, Pirovano W, Gittenberger E, Schilthuizen M (2012) The complete mitogenome of Cylindrus obtusus (Helicidae, Ariantinae) using Illumina next generation sequencing. BMC Genomics 13: 114. doi: 10.1186/1471-2164-13-114

Hatzoglou E, Rodakis GC, Lecanidou R (1995) Complete sequence and gene organization of the mitochondrial genome of the land snail Albinaria coerulea. Genetics 140(4): 1353-1366.

He Y, Jones J, Armstrong M, Lamberti F, Moens M (2005) The mitochondrial genome of Xiphinema americanum sensu stricto (Nematoda: Enoplea): Considerable economization in the length and structural features of encoded genes. Journal of Molecular Evolution 61: 819-833. doi: 10.1007/s00239-005-0102-7

He ZP, Dai XB, Zhang S, Zhi TT, Lun ZR, Wu ZD, Yang TB (2014) Complete mitochondrial genome of the giant African snail, Achatina fulica (Mollusca: Achatinidae): a novel location of putative control regions (CR) in the mitogenome within Pulmonate species. Mitochondrial DNA 27(2): 1-2.

Hirano T, Kameda Y, Kimura K, Chiba S (2014) Substantial incongruence among the morphology, taxonomy, and molecular phylogeny of the land snails Aegista, Landouria, Trishoplita, and Pseudobuliminus (Pulmonata: Bradybaenidae) occurring in East Asia. Molecular Phylogenetics and Evolution 70: 171-181. doi: 10.1016/j.ympev.2013.09.020 
Hugall A, Moritz C, Moussalli A, Stanisic J (2002) Reconciling paleodistribution models and comparative phylogeography in the Wet Tropics rainforest land snail Gnarosophia bellendenkerensis (Brazier 1875). PNAS 99(9): 6112-6117. doi: 10.1073/pnas.092538699

Kerney MP, Cameron RAD (1979) A field guide to the land snails of Britain and northwestern Europe. London, Collins, 288 pp.

Kinouchi M, Kanaya S, Ikemura T, Kudo Y (2000) Detection of tRNA based on the cloverleaf secondary structure. Genome Information 11: 301-302.

Lowe TM, Eddy SR (1997) TRNAscan-SE: a program for improved detection of transfer RNA genes in genomic sequence. Nucleic Acids Research 25: 955-964. doi: 10.1093/ nar/25.5.0955

Merritt TJS, Shi L, Chase MC, Rex MA, Etter RJ, Quattro JM (1998) Universal cytochrome $\mathrm{b}$ primers facilitate intraspecific studies in molluscan taxa. Molecular Marine Biology and Biotechnology 7: 7-11.

MOA, AQSIQ (2012) The List of Quarantine Pests of the People's Republic of China of the Entry of Plants. Beijing, China.

Ojala D, Montoya J, Attardi G (1981) tRNA punctuation model of RNA processing in human mitochondrial. Nature 290(5806): 470-474. doi: 10.1038/290470a0

Palumbi S, Martin A, Romano S, Mcmillan WO, Stice L, Grabowwski G (1991) The Simple Fool's Guide to PCR. Department of Zoology, University of Hawaii, Honolulu.

Perna NT, Kocher TD (1995) Patterns of nucleotide composition at fourfold degenerate sites of animal mitochondrial genomes. Journal of Molecular Evolution 41: 353-358. doi: 10.1007/BF01215182

Raay TJ, Crease TJ (1994) Partial mitochondrial DNA sequence of the crustacean Daphnia pulex. Current Genetics 25: 66-72. doi: 10.1007/BF00712970

Saccone C, De GC, Gissi C, Pesole G, Reyes A (1999) Evolutionary genomics in Metazoa: the mitochondrial DNA as a model system. Gene 238(1): 195-209. doi: 10.1016/S03781119(99)00270-X

Scott B (1996) Phylogenetic relationships of the Camaenidae. Journal of Molluscan Studies 62: 65-73. doi: 10.1093/mollus/62.1.65

Steinke D, Albrecht C, Pfenninger M (2004) Molecular phylogeny and character evolution in the Western Palearctic Helicidae s.l. (Gastropoda: Stylommatyophora). Molecular Phylogenetics and Evolution 32: 724-734. doi: 10.1016/j.ympev.2004.03.004

Tamura K, Peterson D, Stecher G, Nei M, Kumar S (2011) MEGA5: molecular evolutionary genetics analysis using maximum likelihood, evolutionary distance, and maximum parsimony methods. Molecular Biology and Evolution 28: 2731-2739. doi: 10.1093/molbev/ msr121

Terrett JA, Miles S, Thomas RH (1995) Complete DNA sequence of the mitochondrial genome of Cepaea nemoralis (Gastropoda: Pulmonata). Journal of Molecular Evolution 42: 160-168. doi: 10.1007/BF02198842

USDA (2008) Port of Tacoma Cernuella virgata (C. virgata) Eradication Program in Pierce County, Washington, $12 \mathrm{pp}$. 
Wade CM, Hudelot C, Davison A, Naggs F, Mordan PB (2007) Molecular phylogeny of the helicoid land snails (Pulmonata: Stylommatophora: Helicoidea), with special emphasis on the Camaenidae. Journal of Molluscan Studies 73: 411-415. doi: 10.1093/mollus/eym030

Wang JP, Nie XP, Cao TW, Zhang M, Guo YP, Ma EB, Zhang XN (2012) Analysis of complete mitochondrial genome of Sasakia charonda coreana (Lepidoptera, Nymphalida). Acta Zootaxonomica Sinica 37(1): 1-9.

Wang P, Yang HF, Zhou WC, Hwang CC, Zhang WH, Qian ZX (2014) The mitochondrial genome of the land snail Camaena cicatricosa (Müller, 1774) (Stylommatophora: Camaenidae): Presently known as the first in Camaenidae. ZooKeys 451: 33-48. doi: 10.3897/ zookeys.451.8537

White TR, Conrad MM, Tseng R, Balayan S, Golding R, Martins AM, Dayrat BA (2011) Ten new complete mitochondrial genomes of pulmonates (Mollusca: Gastropoda) and their impact on phylogenetic relationships. BMC Evolutionary Biology 11(1): 295. doi: 10.1186/1471-2148-11-295

Wyman SK, Jansen RK, Boore JL (2004) Automatic annotation of organellar genomes with DOGMA. Bioinformatics 20(17): 3252-3255. doi: 10.1093/bioinformatics/bth352

Yamazaki N, Ueshima R, Terrett JA, Yokobori S, Kaifu M, Segawa R, Kobayashi T, Numachi K, Ueda T, Nishikawa K, Watanabe K, Thomas RH (1997) Evolution of Pulmonate Gastropod mitochondrial genomes: comparisons of gene organizations of Euhadra, Cepaea and Albinaria and implications of unusual tRNA secondary structures. Genetics 145: 749-758. Yang HR, Zhang JE, Luo H, Luo MZ, Guo J, Deng ZX, Zhao BL (2014) The complete mitochondrial genome of the mudsnail Cipangopaludina cathayensis (Gastropoda: Viviparidae). Mitochondrial DNA 16: 1-3.

Yu DJ, Xu L, Nardi F, Li JG, Zhang RJ (2007) The complete nucleotide sequence of the mitochondrial genome of the oriental fruit fly, Bactrocera dorsalis (Diptera: Tephritidae). Gene 396: 66-74. doi: 10.1016/j.gene.2007.02.023

Zhang DX, Hewitt GM (1997) Insect mitochondrial control region: A review of its structure, evolution and usefulness in evolutionary studies. Biochemical Systematics and Ecology 25: 99-120. doi: 10.1016/S0305-1978(96)00042-7 